\title{
Innovative enhancements for Annals of Palliative Medicine
}

\author{
Charles B. Simone II \\ New York Proton Center, New York, NY, USA \\ Correspondence to: Charles B. Simone II, MD. New York Proton Center, 225 East 126th Street, New York, NY 10035, USA. \\ Email: csimone@nyproton.com.
}

Submitted Jul 24, 2020. Accepted for publication Jul 31, 2020.

doi: 10.21037/apm-2020-07

View this article at: http://dx.doi.org/10.21037/apm-2020-07

With the recent successes of Annals of Palliative Medicine, including the journal becoming indexed in Science Citation Index Expanded (SCIE) by Clarivate Analytics in January 2019 (1) and receiving its impact factor in June 2019 for the 2018 citation year (2), I am excited to discuss several recent innovative changes and policies that have been initiated for Annals of Palliative Medicine.

\section{Reporting guideline checklists}

Authors are now asked to submit their manuscript along with a reporting guideline checklist. This reporting guideline is a simple and structured tool that provides a minimum list of information necessary to ensure a manuscript can be understood by readers, replicated by a researcher, and/or useful to make clinical decisions. The reporting guideline presents a clear list of reporting items to appear in a manuscript and explain how the list was developed. Large-scale efforts to optimize reporting of research studies date back decades, including the QUOROM statement (quality of reporting of metaanalyses) for meta-analyses or randomized controlled trials (3) and the updated PRISMA (preferred reporting items for systematic reviews and meta-analyses) (4).

To ensure research quality and transparency and to better inform readers, this guideline checklist is now published in Annals of Palliative Medicine online with accepted manuscripts for all major article types. Specifically, Original Articles should be prepared according to the EQUATOR research reporting guidelines (5). Authors are asked to provide a statement at the end of the Introduction section of their manuscript to indicate which reporting checklist was followed (Table 1), and a Reporting Checklist statement is also included as a footnote.

\section{Transparent peer review process}

As with transparency in submitted manuscripts detailed above, Annals of Palliative Medicine is similarly commitment to openness, accountability, and transparency throughout the peer review process. Therefore, Annals of Palliative Medicine has instituted a transparent peer review process as an option for all manuscripts submitted since March 2020. This change will promote increased research integrity and reproducibility. Furthermore, by disclosing the journal's peer review process, readers will benefit by seeing the information on which the editorial office bases its decisions to publish papers, and they can also gain more insights into the merits of a study.

When manuscript is now submitted to the Annals of Palliative Medicine online submission portal, authors are asked in the portal if they agree to the publication of the peer review file (the record of reviewer reports and author replies) along with their accepted manuscript after the peer review process. If so, the peer review file appears as a footnote for published articles. Of note, the choice of an author to include or not include the peer review file will not affect any subsequent editorial decisions.

Additionally, by accepting the review task, journal reviewers agree to the anonymous publication of their comments, and they will be notified of this in the reviewer invitation. This change will also better acknowledge the hard work of peer reviewers for Annals of Palliative Medicine, enabling their article assessments to now reach a much larger audience. The identity of the reviewer, however, continues to remain confidential. 
Table 1 Guidelines and checklists by manuscript type

\begin{tabular}{lll}
\hline Study type & Guideline & Checklist \\
\hline Randomized controlled trial & CONSORT (CONsolidated Standards Of Reporting Trials) & CONSORT checklist \\
Nonrandomized design & $\begin{array}{l}\text { TREND (Transparent Reporting of Evaluations with Nonrandomized } \\
\text { Designs) }\end{array}$ & TREND checklist \\
$\begin{array}{l}\text { Observational studies in } \\
\text { epidemiology }\end{array}$ & $\begin{array}{l}\text { STROBE (STrengthening the Reporting of Observational studies in } \\
\text { Epidemiology) }\end{array}$ & STROBE checklist \\
$\begin{array}{l}\text { Diagnostic accuracy study } \\
\text { meta-analysis }\end{array}$ & STARD (STAndards for Reporting of Diagnostic Accuracy Studies) & STARD checklist \\
Animal research & PRISMA (Preferred Reporting Items for Systematic Reviews and & PRISMA checklist \\
Clinical practice guidelines & Meta-Analyses) & AGREE guidelines/RIGHT guidelines \\
\hline
\end{tabular}

\section{Update of author instructions}

The Guidelines for Authors available on the Annals of Palliative Medicine website at http://apm.amegroups.com/ pages/view/guidelines-for-authors has been updated to reflect the new Reporting Guideline requirement and to clarify article requirements and guidelines.

\section{Website content updates: data sharing and conflicts of interest}

In April 2020, information was added to the Annals of Palliative Medicine website regarding the journal's data sharing policy for authors who have made their study data accessible in a data repository and for authors who are publishing on clinical trials that began enrolling on or after January 1, 2019, in accordance with International Committee of Medical Journal Editors (ICMJE) recommendations (6).

In June 2020, the conflict of interest content on Annals of Palliative Medicine website was updated and the definition of conflict of interest was clarified. Furthermore, each author is now asked to fill out the ICMJE's unified disclosure form (7) and write a conflict of interest statement that is to be included along with the manuscript submission.

\section{Partnership with Publons}

In April 2020, AME Publishing Company, the parent publishing company of Annals of Palliative Medicine, entered an official partnership with Publons. This Clarivate
Analytic Company product provides a platform that allows researchers to track, verify, and be recognized for their peer review and editorial work. These peer review and editorial contributions are displayed on the public Publons profile of the reviewer, which can showcase their scholastic achievements.

As the Annals of Palliative Medicine peer review system is now integrated seamlessly into the Publons platform, reviewers of Annals of Palliative Medicine can now opt in to Publons as part of the review submission process, and the review data can be transferred to Publons upon submission. Each and every reviewer and Editorial Board member of Annals of Palliative Medicine is much appreciated, and their tireless work helps to ensure readers of the journal see and benefit from high article quality content. As with the move to the transparent peer review process, this change will further increase the recognition of the contributions of these expert peer reviewers and also increase engagement by the journal reviewers.

\section{Summary}

Each of these changes has had one singular purpose- to further enhance the content of Annals of Palliative Medicine for our authors and readers. Each change optimizes current best practice in publishing and underscores our commitment to transparency and accountability. As Annals of Palliative Medicine is increasingly viewed as a leading journal by the international palliative care community and is considered a premier journal for original research and review articles in palliative oncology and palliative 
medicine, we are excited to promote these changes that will help to ensure the continued growth and esteem of Annals of Palliative Medicine.

\section{Acknowledgments}

Funding: None.

\section{Footnote}

Provenance and Peer Review: This article was commissioned by the editorial office, Annals of Palliative Medicine. The article did not undergo external peer review.

Conflicts of Interest: The author has completed the ICMJE uniform disclosure form (available at http://dx.doi. org/10.21037/apm-2020-07). CBS II serves as an unpaid Editor-in-Chief of Annals of Palliative Medicine. The author has no other conflicts of interest to declare.

Ethical Statement: The author is accountable for all aspects of the work in ensuring that questions related to the accuracy or integrity of any part of the work are appropriately investigated and resolved.

Open Access Statement: This is an Open Access article distributed in accordance with the Creative Commons Attribution-NonCommercial-NoDerivs 4.0 International License (CC BY-NC-ND 4.0), which permits the noncommercial replication and distribution of the article with the strict proviso that no changes or edits are made and the original work is properly cited (including links to both the formal publication through the relevant DOI and the license). See: https://creativecommons.org/licenses/by-nc-nd/4.0/.

\section{References}

1. Simone CB 2nd. Annals of Palliative Medicine is now indexed in Science Citation Index Expanded (SCIE). Ann Palliat Med 2019;8:102-3.

2. Simone CB 2nd. Annals of Palliative Medicine earns its first official impact factor. Ann Palliat Med 2019;8:352-4.

3. Moher D, Cook DJ, Eastwood S, et al. Improving the quality of reports of meta-analyses of randomised controlled trials: the QUOROM statement. Quality of reporting of meta-analyses. Lancet 1999;354:1896-900.

4. Moher D, Liberati A, Tetzlaff J, et al. Preferred reporting items for systematic reviews and meta-analyses: the PRISMA statement. Int J Surg 2010;8:336-41.

5. EQUATOR Network. Enhancing the QUAlity and Transparency Of health Research. Available online: https:// www.equator-network.org/ (Accessed July 19, 2020).

6. International Committee of Medical Journal Editors. Clinical Trials. Available online: http://www.icmje.org/ recommendations/browse/publishing-and-editorial-issues/ clinical-trial-registration.html (Accessed July 19, 2020).

7. International Committee of Medical Journal Editors. Conflicts of Interest. Available online: http://www.icmje. org/conflicts-of-interest/ (Accessed July 19, 2020).
Cite this article as: Simone CB 2nd. Innovative enhancements for Annals of Palliative Medicine. Ann Palliat Med 2020;9(4):E1E3. doi: 10.21037/apm-2020-07 